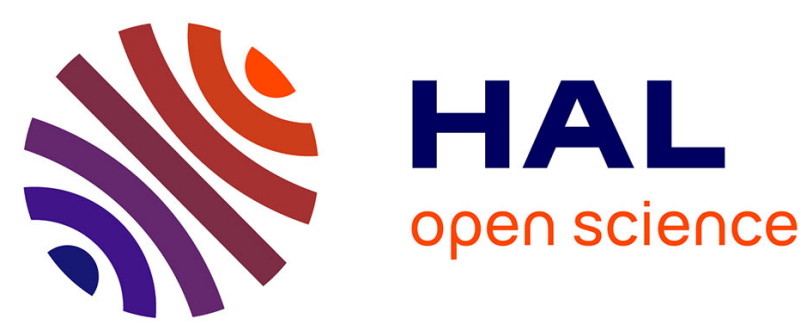

\title{
High Impact Polypropylene Recycling - Mechanical Resistance and LCA Case Study with Improved Efficiency by Preliminary Sensitivity Analysis
}

Michal Kozderka, Bertrand Rose, Vladimír Kočí, Emmanuel Caillaud, Nadia Bahlouli

\section{To cite this version:}

Michal Kozderka, Bertrand Rose, Vladimír Kočí, Emmanuel Caillaud, Nadia Bahlouli. High Impact Polypropylene Recycling - Mechanical Resistance and LCA Case Study with Improved Efficiency by Preliminary Sensitivity Analysis. 12th IFIP International Conference on Product Lifecycle Management (PLM), Oct 2015, Doha, Qatar. pp.541-553, 10.1007/978-3-319-33111-9_49 . hal-01377480

\author{
HAL Id: hal-01377480 \\ https://hal.inria.fr/hal-01377480
}

Submitted on 7 Oct 2016

HAL is a multi-disciplinary open access archive for the deposit and dissemination of scientific research documents, whether they are published or not. The documents may come from teaching and research institutions in France or abroad, or from public or private research centers.
L'archive ouverte pluridisciplinaire HAL, est destinée au dépôt et à la diffusion de documents scientifiques de niveau recherche, publiés ou non, émanant des établissements d'enseignement et de recherche français ou étrangers, des laboratoires publics ou privés. 


\title{
High impact polypropylene recycling - Mechanical resistance and LCA case study with improved efficiency by preliminary sensitivity analysis
}

\author{
Michal Kozderka , Bertrand Rose ${ }^{2}$, Doc. Ing. Vladimír Kočí Ph.D. ${ }^{3}$, Prof. Emmanuel \\ Caillaud $^{4}$, Prof. Nadia Bahlouli ${ }^{5}$ \\ Icube UMR CRNS, Université de Strasbourg, Strasbourg, France;UCHOP, UCT Prague, Praha, \\ Czech Republic \\ mkozderka@unistra.fr, kozderkm@vscht.cz \\ Icube UMR CRNS/Université de Strasbourg, Strasbourg, France \\ bertrand.rose@unistra.fr \\ 3 UCHOP, UCT Prague, Praha, Czech Republic \\ vlad.koci@vscht.cz \\ Icube UMR CRNS/Université de Strasbourg, Strasbourg, France \\ emmanuel.caillaud@unistra.fr \\ Icube UMR CRNS/Université de Strasbourg, Strasbourg, France \\ nadia.bahlouli@unistra.fr
}

\begin{abstract}
Life Cycle Inventory is one of the longest part of the LCA and yet we cannot always get all the necessary data. This study is a methodological point of view on getting a quality results from a case study of polypropylene recycling, based on an intersection of currently used methods of benchmarking the unavailable data, using the sensitivity analysis and the good practices in LCA. The principle is in classification of unavailable data based on their relevance to the results and to the goal and scope definition. The goal is to let the analysts focus on the most important parameters before spending resources on the least relevant missing data. The approach was realized on a case study of High Impact Polypropylene (HIPP) recycling. The LCA study is completed with study of impacts on the mechanical properties of the HIPP.
\end{abstract}

Keywords: LCA, lack of data, data quality, Polypropylene, recycling 


\section{Introduction}

Practitioners of the Life Cycle Assessment (LCA; ISO 14040, 2006) [1] find themselves unfortunately often in a confusing situation. In the same time the best available data are required for all applications [1], [2] but the data available in databases are not entirely representative and the data quality vary in different LCI databases. [3] Different common impact assessment methodologies do not give the same results although their intended use is alike or the same [4]-[6] and neither do even LCA modelling programs. [7]

But LCA and LCA-based methodologies still remains the most efficient way of environmental impact assessment method [8]-[10] and with systems like The EPD International or PEF, an objective tools for product's environmental impact assessment, allowing comparison of equivalent product. [10], [11]

If a LCA practitioners struggled always for the best data possible, they would have to update their data once they finished getting them because the first ones would be already outdated. But every study have some deadline and practitioners need to organize their work in order to work the most efficiently possible.

This Work have two objectives:

a. Describe an approach to help with the difficult data

The idea is to sort the unavailable data in order to put the most energy in the most important missing data.

The method is demonstrated on a LCA of a simple plastic product, typical in the automotive industry.

b. Give the results of a case study we used to test the approach.

We have studied recycling of High Impact Polypropylene, typical for the automotive industry. The LCA study is completed with a study of mechanical properties in function of number of recycling of the one given product.

\section{State of the art and Objectives of the research}

The LCA is one of the most complete tools for environmental impact assessment, but its use is usually expensive and time consuming. [2] Certainly, from the beginning, when a LCA lasted years and has cost millions of dollars it came a long way and actually the duration of LCA is usually counted in months (depending on complexity of the studied product and on the scope of the study) and costs thousands of dollars.

The development in LCA in the last years is not any more focused on the methodology itself, but more on the data quality [3]-[7], [12], [13] better assessment in the categories of impact in toxicology and ecotoxicology [14] and on advanced systems based on Product category rules (PCR), allowing to compare equivalent products. [9], [11]

Quality of the LCA methodology is already proved by thousands of studies. Latest development on the field of the LCA methodology itself is composed of studies of smaller scale, while the growing field is rather in the PCR-based systems. But improving of the methodology and studies of improvement of efficiency, quality and completeness of LCA are still going on.

In this study we connect three approaches to bring a way of improving the resource efficiency in the Life Cycle Inventory (LCI) stage: 
a. use of sensitivity analysis as a tool to sort unavailable data according to the result's sensitivity to them [15]

b. complete model of sensitivity analysis considering multiple impact categories [16]

c. qualitative approach common in LCA methodology [2].

The objective is to let the LCA practitioner simply sort the unavailable parameters according to their relevance to the desired results and let him distribute his resources on data collection efficiently.

\section{Methods}

\subsection{Preliminary sensitivity analysis}

As a method we have chosen the sensitivity analysis. Its role is basically to verify quality of used parameters, [2] but its ability to sort importance of unavailable data is often overlooked. The principle is in analyzing estimations of unavailable parameters. Then the sensitivity analysis can give us an order of parameters depending on their influence to the LCA results. The idea of the method comes from the LCA's iterativity. Normally we perform the sensitivity analysis in the end of the study in order to find parameters that could easily influence the study and eventually we have to come back and precise the most important parameters. This time we only make a step forward and test an estimations of missing parameters before trying to get the real numbers. Such model helps to understand the role of missing parameters and especially it allows performing the sensitivity analysis itself. A similar method is used as proposed by Bengt Steen (1997), [15] for a single impact category approach. In our case we combined the method with the sensitivity analysis model proposed by Björklund (2002) [16] to enlarge to a multiple impact category use.

The inconvenience of iterativity in this approach is that every time we change any input data, the result of the sensitivity analysis will change too. This is why improvement of several important parameters at once is advantageous.

Contrary to the original method we do not compare only the results mentioned in the goal of the study, but all the absolute results. The borders of our approach are given by the scope of the study and the goals of the study define only a group of parameters with higher priority.

So in addition to the original methods, to be sure not to overlook any important aspect of the study, we review the goal and scope definition to find a restrictions that would make us adjust the final priority order of unavailable data or parameters. Because of large number of possible goals and uses of LCA, every case study needs probably a unique approach.

In our case study the scope is defined as all the relevant processes and energies, neglecting maintenance of machines, activities of employees and their facilities and construction and energy consumption of buildings. No matter the results of the sensitivity analysis, the data inside the scope definition should not be neglected. The goal of the study is to search for the differences between scenarios with virgin and recycled High Impact Polypropylene. Therefore we should give priority to the data participating on the goal of the study. Two categories of results will then appear. The parameters participating on the goal of the study and a complementary parameters.

The objective of the preliminary sensitivity analysis is not to neglect as much processes as possible. Even estimated flows of constant value in a comparative study can help to understand the role of eventual difference of impacts between the two studied solutions, as proposed by Gehin, Zwolinski and Brissaud for a brick LCI model. [17] 
a. The first step is then modelling the scenario with estimation of all difficult data.

b. The second step is to review the goals and scope and take actions to prevent any violation of goal and scope definition of the whole study. This step is different for every case study. In our case it was a precaution of not neglecting any data inside the scope definition and giving priority to all missing parameters, related to the goal of the study - difference between impacts of virgin and recycled HIPP product.

c. The third step consists of a preliminary sensitivity analysis itself.

For an arbitrary level of significant sensitivity, usual choice is 5 or 10 percent, we will get the results in two forms. Absolute and relative, where $x$ will be the estimated parameter value, $x_{c}$ a critical value of the parameter that would increase or decrease any impact category over the level of significant sensitivity and $\Delta x$ will be a relative parameter variance, useful for the parameter classification as proposed by Bengt Steen (1997), [15].

\subsection{LCA}

The study of environmental properties was done as a classical comparative LCA study, according to ISO 14040 (2006) [1]. The desired results are the differences between environmental impacts of virgin HIPP and HIPP with different ratios of recycled matter.

The goal of the LCA study then was: Identify the changes in environmental impacts between products made of virgin and recycled HIPP. The only available product to be studied was a testing rod. Not a typical part, used in the automotive industry. After consultation with a car body parts producer, it was decided to keep studying the testing rod, as its lifecycle was similar to the most HIPP parts that he produces. That means rather regional plastic and part producers, transports by a truck and shredding of used parts to produce parts of the same or similar purpose which is defined as a closed loop recycling. [2], [17]. Ideally, the results should be applicable not only to the studied product, but for mostly simple PP injected parts.

The lifecycle of the testing rod was similar, but not exactly the same as for the most car parts.

During the study we decided to add two complementary hypothetical scenarios in order to simulate more closely a serial production.

For the Lifecycle impact assessement (LCIA) we chose the ready-made methodology CML, which is well adapted to the production industry [2] and widely used in the automotive industry. [18]-[20] The choice of the CML methodology was verified in comparison with several other available methodologies, ReCiPe (midpoint and endpoint approach), I02+ v2.1 and EDIP 2003/1997. In similar impact categories we observed the difference between the virgin HIPP and mix of 50\% virgin and 50\% recycled HIPP. The results of a recycled HIPP scenario in all Lifecycle Impact Assessment (LCIA) methodologies are expressed relatively to the results of virgin HIPP, where virgin HIPP represents $100 \%$ impact.

Figure 1 shows a good coherence between LCIA methodologies in categories of fossil fuels depletion, global warming potential (GWP), acidification, eutrophication, ozone depletion, photochemical ozone creation, particulate matter formation and ionizing radiation. Contrary, in the categories of abiotic or metal depletion, human toxicity, terrestrial and freshwater ecotoxicity the LCIA methodologies does not even agree whether the use of recycled HIPP has a positive or negative impacts.

We decided to keep CML, which remains between the highest and the lowest results in all the categories except for the human toxicity, where the CML result is the highest. 


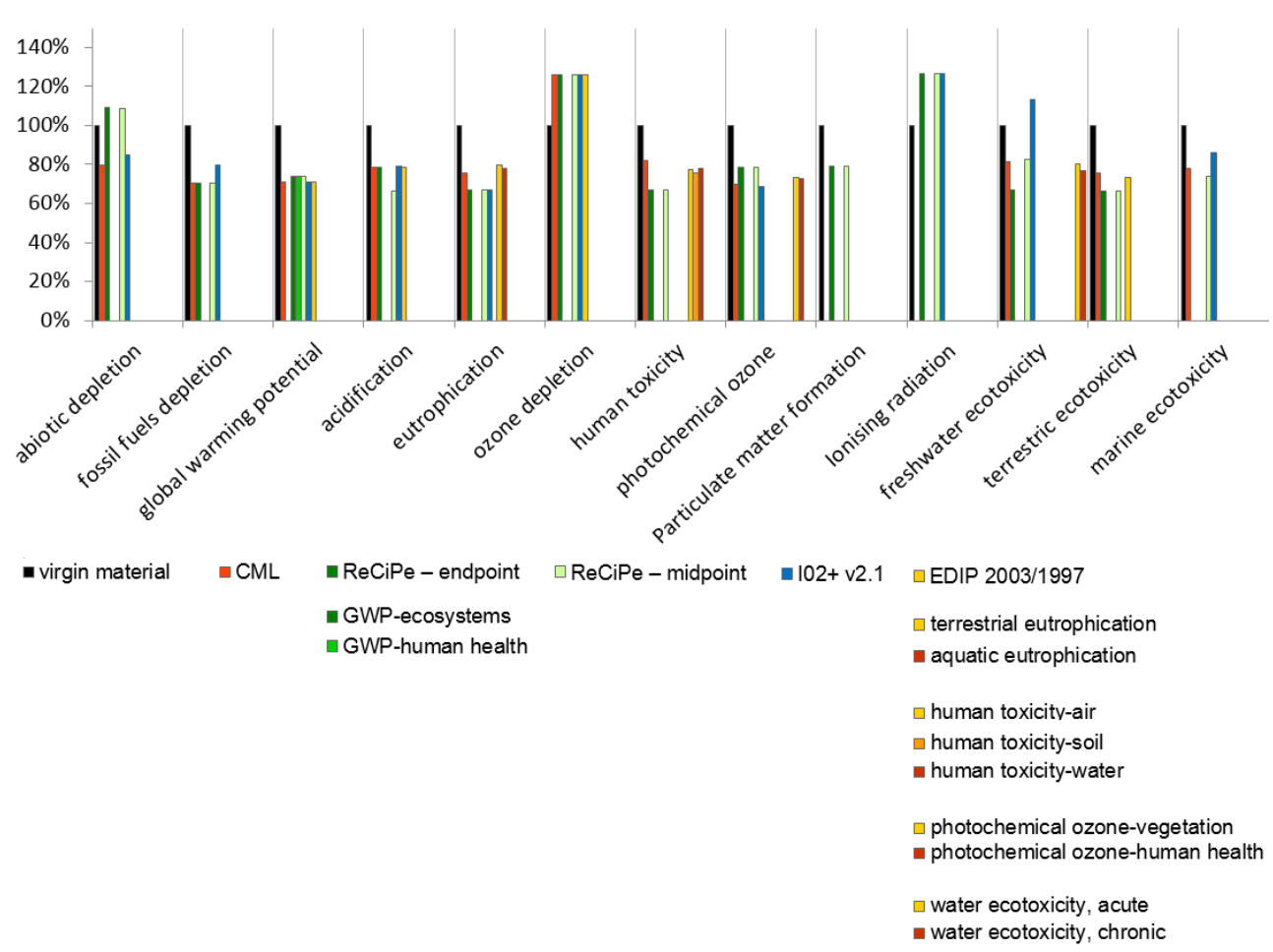

Figure 1 Comparison of LCIA methodologies on an intermediate scenario (truck transports) In all categories virgin material represents $100 \%$ of the impact, while the other columns represent the relative impact of $50 \%$ recycled material, calculated with various LCIA

\subsection{Mechanical behavior}

The material was reprocessed $0,3,6,9$ and 12 times and two characterizations was observed. From the material point of view - Molecular weight and rheological characterization and from the mechanical point of view - Tensile behavior in small and large stress specter.

An unfilled high impact polypropylene was used. Referenced as SABIC@PP, grade 108MF97, composed by a PP matrix containing $22 \%$ of ethylene propylene rubber (EPR) particles. A low amount of talc was also detected $(<0.5 \%)$, thus the material is assumed as a two phases material. 


\section{4 experimentation}

The product lifecycle was modelled according to a practice of an important producer of plastic car body parts. The result is a closed loop scenario where the recovered HIPP is used to produce the same product, or at least the same type of product. See the model on the Figure 2.

The case study was modelled and assessed in a software tool GaBi V4. Originally it was supposed that choice of the LCA software wouldn't have any consequences to the results. However, the latest studies show that the results can be influenced due to a minor errors in the programs. [7]

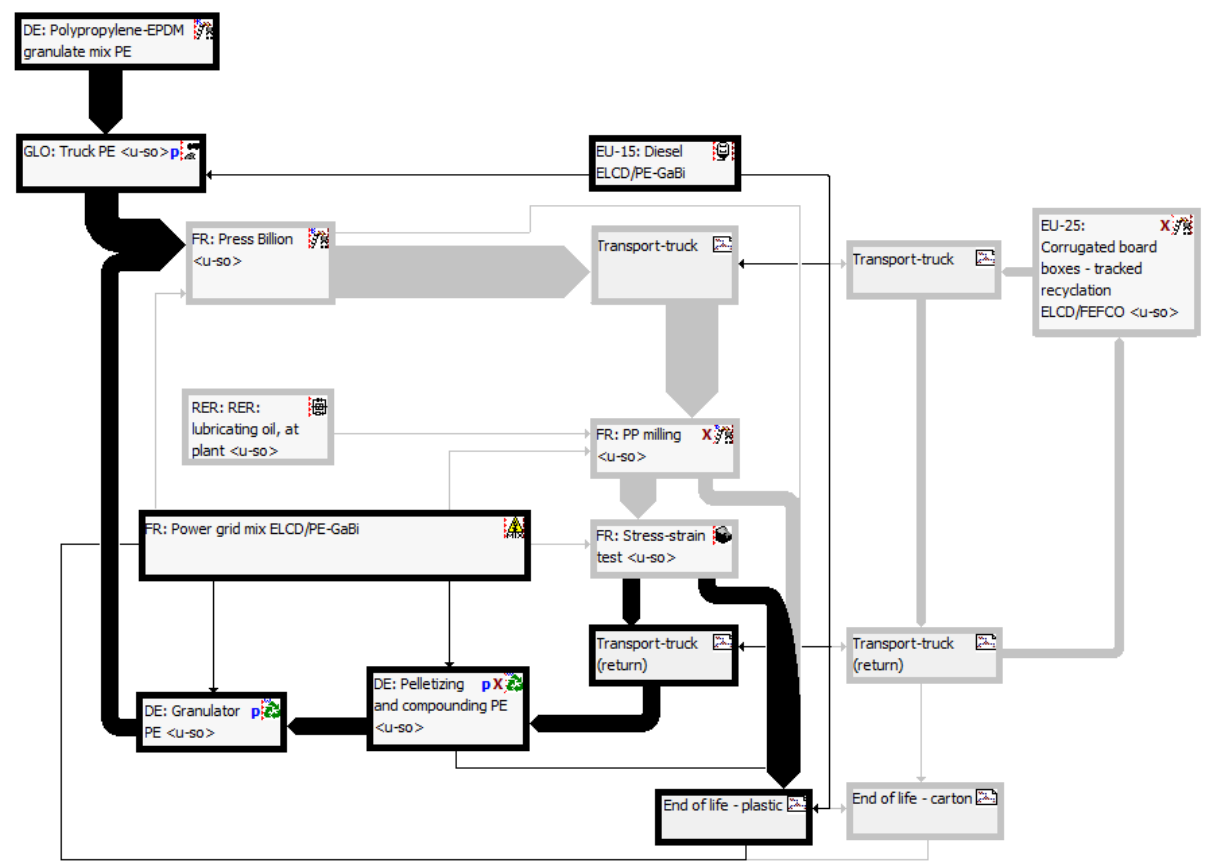

Figure 2: Product lifecycle scenario. Processes and flows in black do change between scenarios, processes and flows in grey remain constant.

Flows are scaled according to their weigh. Consumption and production of electric energy are represented only by their direction, not scale.

During the LCI phase we fell on 5 undocumented processes, see table 1. Even if all the production processes are available, some parameters may remain hidden. In our case, even if we had concerned machines at disposition, we didn't have any measure instruments for energy consumption of a medium voltage machines. Other cases are retailers who don't give out origin of the goods, because they consider them as a strategic information, or transport societies who simply do not collect data for a specific journeys. 


\begin{tabular}{|c|l|}
\hline Dimension & Estimated quantity $x$ \\
\hline $\begin{array}{c}\text { Distance from HIPP granulate } \\
\text { producer to the part producer }\end{array}$ & $500 \mathrm{~km}$ \\
\hline $\begin{array}{c}\text { Distance from the transport society } \\
\text { stock to the customer }\end{array}$ & $80 \mathrm{~km}$ \\
\hline Milling - electric energy consumption & $0,1 \mathrm{kWh}$ \\
\hline Milling - lubricant consumption & $0,01 \mathrm{~kg}$ of lubricating oil \\
\hline $\begin{array}{c}\text { Stress-strain test - electric energy } \\
\text { consumption }\end{array}$ & $1,2 \mathrm{kWh}$ \\
\hline
\end{tabular}

Table 1: Estimated unavailable parameters

To save time and work most efficiently possible, we needed to sort the data according to their relevance to the study. This sorting was performed on two levels. Qualitative and quantitative.

In the first time, we looked at the goal definition and at the lifecycle model on the qualitative level. The goal of the study is to find out if recycled HIPP is better than the virgin HIPP. Therefore we search for the difference between these two materials.

In the model we searched for all the processes that can have any influence on the difference between the two studied materials. In other words we needed to search for processes that changes between the virgin and recycled scenarios. This research was based on the nature of modelled processes and verified by comparing the inputs and outputs between scenarios. See the distribution of processes and flows on Figure 2.

Between the undocumented processes and flows, only the transport from the producer of HIPP granulate was found as a process, participating on the defined goal. The dimensions of the other undescribed processes did not change in any way between scenarios with different ratio of recycled HIPP.

In the second step we performed a sensitivity analysis on an estimation of unknown data. Table 2 show the results: 


\begin{tabular}{|c|c|c|c|c|c|}
\hline Dimension & $\begin{array}{l}\text { Estimated } \\
\text { quantity } \\
x\end{array}$ & $\begin{array}{l}\text { Critical } \\
\text { parameter } \\
\text { dimension } \\
x_{c}\end{array}$ & $\begin{array}{l}\text { Absolute } \\
\text { critical } \\
\text { variance } \\
\Delta x_{c}\end{array}$ & $\begin{array}{l}\text { Critical \% } \\
\text { parameter } \\
\text { variance } \\
\Delta x_{c}\end{array}$ & $\begin{array}{l}\text { Most } \\
\text { sensitive } \\
\text { impact } \\
\text { category }\end{array}$ \\
\hline $\begin{array}{l}\text { Distance from } \\
\text { HIPP } \\
\text { granulate } \\
\text { producer to the } \\
\text { part producer }\end{array}$ & $500 \mathrm{~km}$ & $3575 \mathrm{~km}$ & 3075 km & $615 \%$ & $\begin{array}{l}\text { Human } \\
\text { toxicity }\end{array}$ \\
\hline $\begin{array}{l}\text { Stress-strain } \\
\text { test - electric } \\
\text { energy } \\
\text { consumption }\end{array}$ & $1,2 \mathrm{kWh}$ & $\begin{array}{l}1,3105 \\
\mathrm{kWh}\end{array}$ & $\begin{array}{l}0,1105 \\
\mathrm{kWh}\end{array}$ & $9 \%$ & $\begin{array}{l}\text { Ozone } \\
\text { layer } \\
\text { depletion }\end{array}$ \\
\hline $\begin{array}{l}\text { Milling } \\
\text { lubricant } \\
\text { consumption }\end{array}$ & $\begin{array}{l}0,01 \mathrm{~kg} \text { of } \\
\text { lubricating } \\
\text { oil }\end{array}$ & $\begin{array}{l}0,0148 \mathrm{~kg} \\
\text { of } \\
\text { lubricating } \\
\text { oil }\end{array}$ & $\begin{array}{l}0,0048 \mathrm{~kg} \\
\text { of } \\
\text { lubricating } \\
\text { oil }\end{array}$ & $48 \%$ & $\begin{array}{l}\text { freshwater } \\
\text { aquatic } \\
\text { ecotoxicity }\end{array}$ \\
\hline $\begin{array}{l}\text { Milling - } \\
\text { electric energy } \\
\text { consumption }\end{array}$ & $0,1 \mathrm{kWh}$ & $\begin{array}{l}0,215 \\
\mathrm{kWh}\end{array}$ & $\begin{array}{l}0,115 \\
\mathrm{kWh}\end{array}$ & $115 \%$ & $\begin{array}{l}\text { Ozone } \\
\text { layer } \\
\text { depletion }\end{array}$ \\
\hline $\begin{array}{l}\text { Distance from } \\
\text { the transport } \\
\text { society stock to } \\
\text { the customer }\end{array}$ & $80 \mathrm{~km}$ & $1630 \mathrm{~km}$ & $1550 \mathrm{~km}$ & $1938 \%$ & $\begin{array}{l}\text { Human } \\
\text { toxicity }\end{array}$ \\
\hline
\end{tabular}

Table 2: Sensitivity analysis results. As a border significant sensitivity we chose $5 \%$ change of any midpoint impact category.

The first line in bold correspond to a parameter that was identified as a contributor on the goal of the study. This parameter gets priority before the other complementary parameters. However, the sensitivity analysis shows that the study is not very sensitive to this parameter. In the target country the distance couldn't rise over $1500 \mathrm{~km}$ and therefore it could never reach the critical variance and any impact could never rise or decrease above the significant level of $5 \%$.

The same situation appears for the distance from the transport society stock to the customer. Therefore it can be roughly estimated without doing any harm to the study. But we should be more careful with the electric energy and lubricating oil consumptions. Even if they do not directly participate on the goal of the study, they do put the results in a real circumstances, showing how important is the difference between virgin and recycled HIPP, compared to their entire lifecycle. 


\section{Results}

\subsection{Preliminary sensitivity analysis}

The timesaving is difficult to account for due to variability of the LCA applications, we could never know how much time we would spend on a parameter we eventually did not try to search for.

In our case, we found one complementary parameter that could never reach the level of significant change in any impact category. The practitioner might then make a quick estimation based on his own experience with goods distribution, without doing any harm to the study.

Stress strain test and lubricating oil consumption was clearly identified as processes that need more research, while electric energy consumption of milling, that have the relative critical variance higher than $100 \%$ gives some space for substitution or estimation.

Iterativity, which is often perceived as an unpleasant quality that makes the studies longer, gives a precious advantage in the preliminary sensitivity analysis. Whenever we get any precisions to the unavailable parameters, the sensitivity of the whole study to these parameters can be quickly reviewed and help to decide if we need to continue with more precisions or if the current knowledge is sufficient to stop the research and put more energy to the research of another unknown parameter.

The most interesting result is probably the critical variance of distance from the HIPP granulate producer to the part production unit. The combination of our qualitative and quantitative approach seems ambiguous. One says that the parameter should get priority before the other parameters, the other says that no matter the choice this parameter could never make a significant change of the results.

This is a case where the qualitative criteria works as a protection of the good practices in LCA. The goal of the study is a translation of the reason why the study is done. Any other information given by the study are complementary, so even if the parameter may seem unimportant in the sensitivity analysis, we should privilege the quality of the data contributing on the goals of the study. The quantitative result would be just a comforting argument if the parameter really could not be found and we had to make an estimation.

The preliminary sensitivity analysis is not any more valid for the final results, as the parameters get more precise and the results are represented for different ratios of recycled matter, while the preliminary sensitivity analysis was composed only of two scenarios with $0 \%$ and $50 \%$ of recycled HIPP. But the approach is the same for both, preliminary sensitivity analysis and sensitivity analysis of final results, so the tables and data prepared in the beginning of the study can be reused. 


\subsection{LCA}

In the most impact categories, the recycled HIPP got better results than the virgin one. Figure 3 shows that the impacts evolution in function of recycled content ratio is close to a linear function.

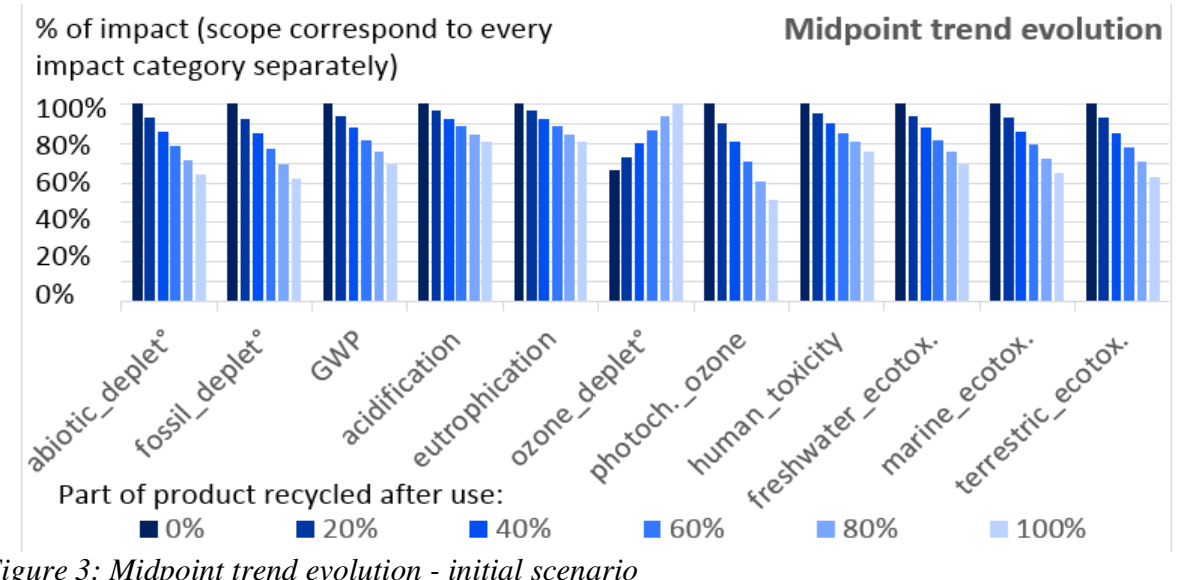

According to our LCIA methodology testing (Figure 1) we get different results in function of LCIA methodology choice in the categories of abiotic depletion, human toxicity and ecotoxicities. In these categories we cannot make a proper conclusion whether recycling is better or not. But in the other categories, fossil fuels depletion, global warming potential, acidification, eutrophication, ozone depletion, photochemical ozone and particulate matter formation all the available methodologies (CML, ReCiPe, I02 and EDIP) show the same tendency and more or less also the same quantities. The CML methodology does not have ionizing radiation impact category. However, all the other methodologies agree on higher impact with higher ratio of recycled plastic.

The only CML impact category in which the recycled HIPP is worse than the virgin granulate, seems to be ozone depletion. The biggest contributor on this category is an electric energy conversion - primary source of energy for the recycling technologies. In the same time, according to CML 2001-09 normalization for EU-25, the contribution of all scenarios on the European pollution in category of ozone depletion is one of the least important, see Figure 4.

Comparison of the real scenario with the two hypothetical scenarios confirms the hypothesis that with cleaner production and transports the importance of virgin HIPP granulate is growing. See Figure 4. The difference between virgin and recycled plastics is always the same, speaking in absolute values, but relatively it grows on importance when the rest of the scenario gets cleaner.

We can see that even in the real scenario with aircraft transport and milling operation the difference between $0 \%$ and $100 \%$ recovery makes $20 \%$ to $40 \%$ in every impact category. That may be an important argument in decision making. 


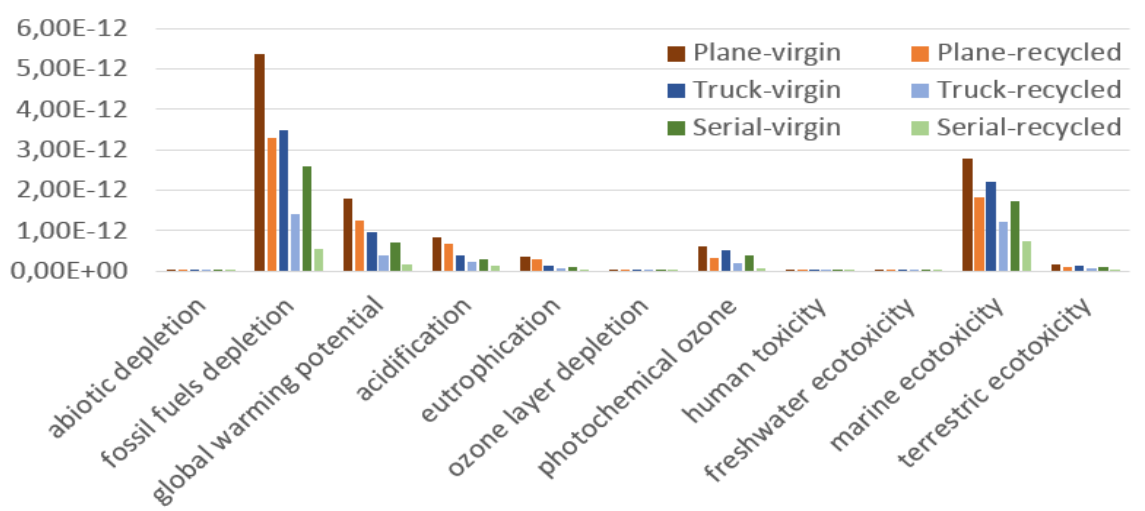

Figure 4: CML 2001-nov.09 normalized - comparison of all three scenarios

\subsection{Mechanical properties}

The material exhibit a classical mechanical behavior under tensile loading [21] after a linear elastic response, a small viscoelastic response appears before the yielding point. After this point, materials deform plastically. (Figures 5-6)

For the yield stress and the yield strain respectively, it can be observed that the recycling process decreases the yield stress. (Figures 7-8)

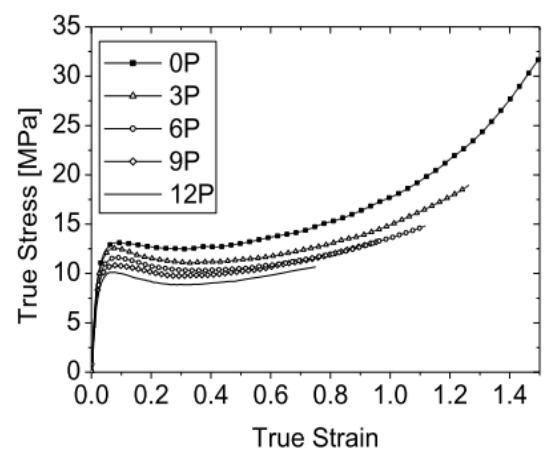

Figure 6: Large domain stress strain

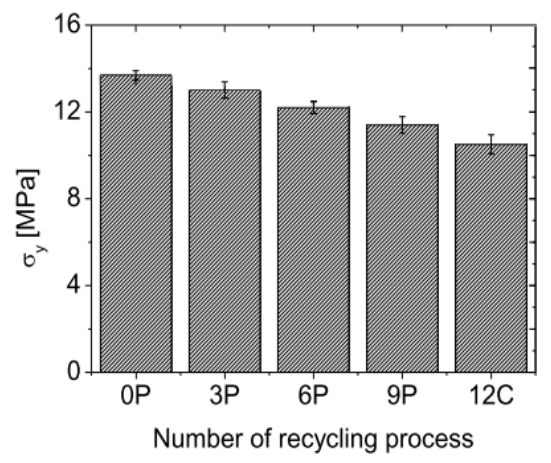

Figure 5: Yield stress

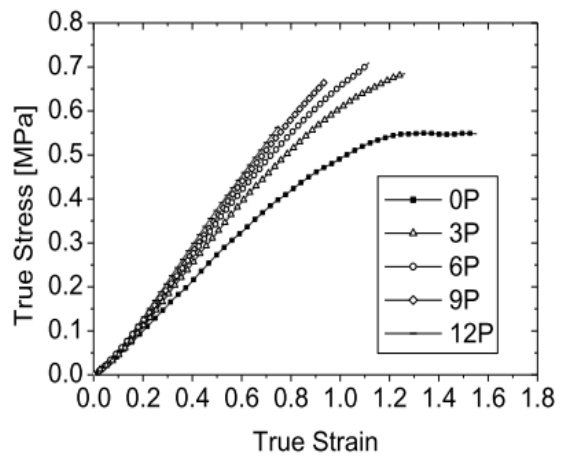

Figure 8: Small domain stress strain

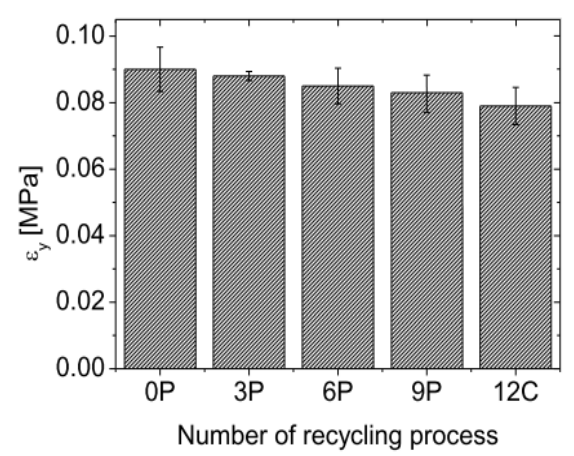

Figure 7: Yield strain 
It seems from the obtained results that the mechanical recycling process has no effect on the Poisson ratio. (Figure 9)

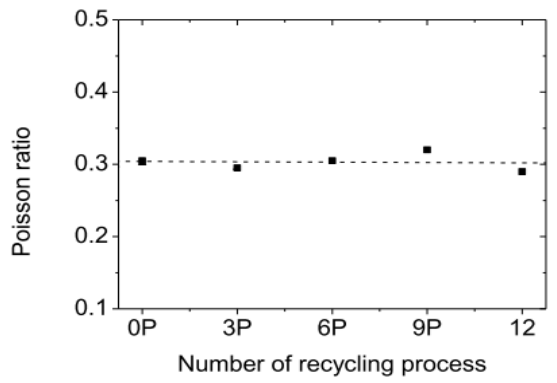

Figure 10: Poisson ratio

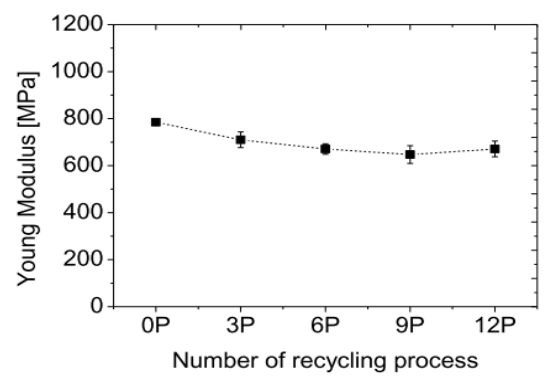

Figure 9: Young modulus

It is observed that the variations of the Young modulus values are of the same order of magnitude than the experimental errors. It could be concluded that a slight effect can be detected between on the virgin material and its respective 12 times recycled derivatives. (Figure 10)

It can be observed that the failure stress decreases linearly with the degradation by the several cycles. At the same time the failure strain is also pretty affected by the different recycling cycles with the same tendency.

On all the tested samples, no necking was observed. However a white zone appeared at the sample's center since relatively low strain. This zone grew until the failure of the specimen. As often mentioned, this is characteristic of a significant amount of cavitation [22], [23] caused by the plastic deformation of polymers near the yield point. This phenomenon corresponds to the evolution of the initial porosity and the initiation of crack type damage.

\section{Conclusion and perspectives}

LCA remains an expensive part of product development and its use is growing slowly in the production industry. More efficient combination of currently used methods is therefore always a useful step forward. In the eventual continuation of this research, including the uncertainty analysis may be a good direction.

Most companies currently using LCA or LCA-based approaches, managed to develop their own timesaving and efficient product category rules and practices. The proposed method can be mostly useful for studies of new product or for new users, especially for more complicated studies with higher numbers of unknown processes.

Every study is different and it is impossible to calculate a universal ratio of time saving with the preliminary sensitivity study. Further work could focus on definition of a precise methods for different product types for example following the CPA/NACE codes in order to improve the efficiency in the systems like The EPD International or PEF/OEF. 


\section{Bibliography}

[1] International Organization for Standardization, "ISO 14040: Environmental Management - Life Cycle Assessment - Principles and Framework," Geneva, 1997.

[2] B. Henrikke and T. Anne-Marie, The Hitch Hiker's Guide to LCA. Lund: Studentlitteratur, 2004.

[3] S. Lasvaux, N. Schiopu, G. Habert, J. Chevalier, and B. Peuportier, "Influence of simplification of life cycle inventories on the accuracy of impact assessment: application to construction products," J. Clean. Prod., vol. 79, pp. 142-151, Sep. 2014.

[4] M. Pizzol, P. Christensen, J. Schmidt, and M. Thomsen, "Eco-toxicological impact of 'metals' on the aquatic and terrestrial ecosystem: A comparison between eight different methodologies for Life Cycle Impact Assessment (LCIA)," J. Clean. Prod., vol. 19, no. 6-7, pp. 687-698, Apr. 2011.

[5] M. Pizzol, P. Christensen, J. Schmidt, and M. Thomsen, "Impacts of 'metals' on human health: a comparison between nine different methodologies for Life Cycle Impact Assessment (LCIA)," J. Clean. Prod., vol. 19, no. 6-7, pp. 646-656, Apr. 2011.

[6] J. Reap, F. Roman, S. Duncan, and B. Bras, "A survey of unresolved problems in life cycle assessment," Int. J. Life Cycle Assess., vol. 13, pp. 374-388, 2008.

[7] I. T. Herrmann and A. Moltesen, "Does it matter which Life Cycle Assessment (LCA) tool you choose? - a comparative assessment of SimaPro and GaBi," J. Clean. Prod., vol. 86, pp. 163-169, Jan. 2015.

[8] M. Gaussin, G. Hu, S. Abolghasem, S. Basu, M. R. Shankar, and B. Bidanda, "Assessing the environmental footprint of manufactured products: A survey of current literature," Int. J. Prod. Econ., vol. 146, no. 2, pp. 515-523, Dec. 2013.

[9] N. P. Kirana Chomkhamsri, “Analysis of Existing Environmental Footprint Methodologies for Products and Organizations: Recommendations, Rationale, and Alignment," Ispra, 2011.

[10] E. Commission, "COMMISSION RECOMMENDATION of 9 April 2013 on the use of common methods to measure and communicate the life cycle environmental performance of products and organisations," Off. J. Eur. Union, vol. 124, no. 1, 2013.

[11] N. Minkov, L. Schneider, A. Lehmann, and M. Finkbeiner, “Type III Environmental Declaration Programmes and harmonization of product category rules: status quo and practical challenges," J. Clean. Prod., vol. 94, pp. 235-246, May 2015.

[12] M. Guo and R. J. Murphy, "LCA data quality: sensitivity and uncertainty analysis.," Sci. Total Environ., vol. 435-436, pp. 230-43, Oct. 2012. 
[13] J. Zhou, V. W.-C. Chang, and A. G. Fane, “An improved life cycle impact assessment (LCIA) approach for assessing aquatic eco-toxic impact of brine disposal from seawater desalination plants," Desalination, vol. 308, pp. 233-241, Jan. 2013.

[14] D. van de M. and M. Z. H. R.K. Rosenbaum, T.M. Bachmann, L.S. Gold, M.A.J. Huijbregts, O. Jolliet, R. Juraske, A. Koehler, H.F. Larsen, M. MacLeod, M.D. Margni, T.E. McKone, J. Payet, M. Schuhmacher, "USEtox - The UNEP-SETAC toxicity model: Recommended characterisation factors for human toxicity and freshwater ecotoxicity in life cycle impact assessment," Int. J. Life Cycle Assess., vol. 13, no. 7, pp. 532-546, 2008.

[15] B. Steen, "On uncertainty and sensitivity of LCA-based priority setting," J. Clean. Prod., vol. 5, no. 4, pp. 255-262, Jan. 1997.

[16] A. E. Björklund, "Survey of approaches to improve reliability in lca," Int. J. Life Cycle Assess., vol. 7, no. 2, pp. 64-72, 2002.

[17] A. Gehin, P. Zwolinski, and D. Brissaud, "Integrated design of product lifecyclesThe fridge case study," CIRP J. Manuf. Sci. Technol., vol. 1, no. 4, pp. 214-220, Jan. 2009.

[18] Renault, "Fluence and Fluence Z.E. Life Cycle Assessment ,” Paris, 2011.

[19] Volkswagen, "The Golf Environmental Commendation Background Report," Wolfsburg, 2010.

[20] Mercedes-Benz, "Life cycle Environmental Certificate for the S 400 HYBRID," Stuttgart, 2009.

[21] N. Bahlouli, D. Pessey, S. Ahzi, and Y. Rémond, "Mechanical behavior of composite based polypropylene: Recycling and strain rate effects," J. Phys. IV, vol. 134, pp. 1319-1323.

[22] F. Addiego, A. Dahoun, C. G'Sell, and J.-M. Hiver, "Characterization of volume strain at large deformation under uniaxial tension in high-density polyethylene," Polymer (Guildf)., vol. 47, no. 12, pp. 4387-4399, May 2006.

[23] C. Fond and C. G'sell, "Localisation des déformations et mécanismes d'endommagements dans les polymères multiphasés," Mécanique Ind., vol. 3, no. 5, pp. 431-438, 2002. 